\title{
Las disputas por los bienes comunes y su impacto en la apropiación de servicios ecosistémicos. La Ley de Protección de Bosques Nativos, en la Provincia de Córdoba, Argentina
}

\author{
Diego A. Cabrol ${ }^{\boxplus}$ \& Daniel M. Cáceres \\ Consejo Nacional de Investigaciones Científicas y Técnicas (CONICET). Facultad de Ciencias Agropecuarias, Universidad \\ Nacional de Córdoba.
}

\begin{abstract}
Resumen. A partir de las cuatro categorías que regulan la propiedad, el acceso y la apropiación de los bienes naturales (i.e., privada, estatal, libre, y comunal), el presente trabajo busca analizar cómo la aprobación de una ley que propone conservar el bosque nativo i) genera procesos de cercamiento de bienes comunes, y ii) impacta de manera diferencial sobre distintos actores sociales. La utilización de técnicas cuantitativas y cualitativas, y la combinación de distintas fuentes de información (i.e., entrevistas a distintos actores sociales, medios masivos de comunicación, documentos gubernamentales) permitió analizar los impactos sociales de la implementación de la Ley de Ordenamiento Territorial para los Bosques Nativos, en la Provincia de Córdoba (Argentina). Los resultados sugieren que la nueva ley prioriza la idea de propiedad privada por sobre las normas consuetudinarias, los arreglos locales y el acceso flexible a los servicios ecosistémicos, propios de la lógica productiva campesina. Los productores capitalizados, con mayor poder económico y político, disponen de mecanismos que les permiten atenuar los efectos restrictivos del nuevo régimen legal y están mejor posicionados para recibir compensaciones monetarias de parte del Estado. Así se generan nuevas condiciones sociales que se traducen en nuevos procesos de exclusión social y en asimetrías económicas entre los productores que operan en un mismo territorio. Son los más vulnerables y con menos poder económico y político (i.e., los campesinos), y los más perjudicados en el nuevo escenario emergente. En un mundo globalizado donde domina la lógica económica de mercado, los ecosistemas nativos están sujetos a una lógica extractivista que prioriza la rentabilidad de corto plazo. Esto genera costos ambientales y sociales elevados. El Estado tiene la responsabilidad de proteger estos ecosistemas a fin de garantizar el bienestar común, pero toda legislación ambiental nueva también debe evaluar sus posibles impactos socioeconómicos.
\end{abstract}

[Palabras clave: exclusión, legislación ambiental, cercamientos, green grabbing]

\begin{abstract}
AвSTRACT. Disputes over common goods and its impact on the appropriation of ecosystem services. The Law for Protection of Native Forests, in the Province of Córdoba, Argentina. Drawing upon the four categories that regulate property, access and appropriation of economic goods (i.e., private, public, open access, and common), this paper aims to analyze how the approval of a law that fosters the conservation of native forests a) promotes the enclosure of common goods, and b) causes different impacts among social actors. By using both quantitative and qualitative methodologies and combining different information sources (interviews to different social actors, mass media, and government documents), we analyzed the socioeconomic impacts of the Law for the Protection of Native Forests, in the Province of Córdoba (Argentina). The results suggest that the new law prioritize the concept of private property over customary norms, local arrangements, and flexible access to ecosystem services which are major features of the social and productive approach followed by subsistence farmers. Capitalized farmers, holding higher economic and political power, have access to different mechanisms allowing them to lessen the new-laws restrictive effects, and have better chances to receive monetary compensations from the Estate for payments for ecosystem services. Thus, new social conditions emerge, which translate into economic asymmetries and processes of social exclusion among different kinds of farmers settled in the same territory. Those who hold lower political and economic power are the most vulnerable ones (i.e., subsistence farmers) and therefore are the most negatively impacted by the new scenario. In a globalized world dominated by an economy market that prioritizes short-term profits, native ecosystems face growing extractivist pressures, which is generating high social and environmental consequences. The State has the responsibility to protect these threatened ecosystems and to guarantee social wellbeing. But all new environmental legislation must also consider its possible socioeconomic impacts.
\end{abstract}

[Keywords: exclusion, environmental legislation, enclosures, green grabbing]

Editor asociado: Matías Mastrangelo

$\checkmark$ diegocabrol@gmail.com
Recibido: 15 de marzo de 2016

Aceptado: 18 de noviembre de 2016 


\section{INTRODUCCIÓN}

Cada sociedad desarrolla un vínculo específico con la naturaleza a fin de lograr satisfacer sus necesidades. Las normasjurídicas y los acuerdos sociales en general, así como la legislación ambiental en particular, determinan las reglas que permiten a los actores sociales acceder o hacer uso de los recursos. La sanción de la Ley de Ordenamiento Territorial de Bosques Nativos en la Provincia de Córdoba (Ley 9814/2010) modificó los marcos legales que regulan el modo en que los distintos actores sociales pueden acceder a los servicios ecosistémicos que proveen los bosques nativos, en particular el aprovisionamiento de madera y leña. Para analizar de qué modo los distintos grupos sociales se ven afectados en este proceso, el presente artículo recupera los conceptos de cercamientos ("enclosures") y bienes comunes. Se utiliza el concepto de cercamientos para hacer referencia a las transformaciones de bienes comunes en bienes de propiedad exclusiva (propiedad privada), con la consecuente pérdida de derechos comunales (Blomley 2007). Los recursos y bienes en general, pueden estar sujetos a cuatro regímenes de uso y apropiación: a) propiedad privada, b) propiedad estatal, c) libre acceso, o d) propiedad comunal (bienes comunes). En este último, el derecho de uso y restricción pertenece a una comunidad identificable, la que a su vez excluye a los externos y regula el aprovechamiento por parte de sus miembros (Feeny et al. 1990). La propiedad comunal es más una relación social que una forma de propiedad ya que son los acuerdos entre los miembros de una comunidad los que determinan de qué modo se deben gestionar los bienes comunes (Helfrich and Hass 2008). Esta propiedad puede estar formalmente legislada o determinada por contratos o convenios comunales sostenidos desde la voluntad o por coerciones sociales (Vercelli and Thomas 2008), y constituye un espacio institucional regido por normas diferentes a las impuestas por el derecho de propiedad privada y los mercados (Benkler 2008). Pero las formas de gestión son dinámicas y las comunidades son susceptibles de verse privadas del acceso a los bienes comunes a través de procesos de cercamiento, que pueden configurar nuevos órdenes económicos como los descriptos por Marx (1976) y Harvey (2004) bajo los conceptos de acumulación originaria y acumulación por desposesión, respectivamente.

En las últimas décadas, los procesos de cercamiento y privatización de bienes comunes se han intensificado en el marco de la estrategia de acumulación por desposesión bien descripta por Harvey (2004). El neoliberalismo, como teoría de prácticas político-económicas que promueve ampliar las libertades empresariales y establecer un marco institucional que garantice los derechos de propiedad privada, mercados fuertes y libertad de comercio (Harvey 2007), afecta los bienes comunes y favorece las condiciones para el proceso de desposesión (Harvey 2004). Resulta interesante destacar que los procesos de acumulación por desposesión no requieren necesariamente la ocurrencia de cambios en los derechos de propiedad. No obstante, afectan el acceso a ciertos recursos por parte de algunos actores sociales (en especial, el de los más vulnerables) (Cáceres 2015).

Desde el liberalismo económico se destacan los peligros que representa la propiedad comunal para la sustentabilidad de los recursos, la eficiencia de su manejo y el crecimiento económico, lo que permite justificar procesos de conversión de propiedad comunal a propiedad privada (Aladró 1993) o estatal (Fernández 1993b). Recientemente se ha acuñado el concepto de "green grabbing" para hacer referencia a la apropiación de tierras y recursos con fines de protección ambiental. En especial, cuando implica una enajenación generalizada de tierras y una reestructuración de las reglas que regulan el acceso, manejo y uso de los recursos (Fairhead et al. 2012). Los cercamientos sobre los recursos naturales comunes configuran lo que Illich (1983) llama "un nuevo orden ecológico", aludiendo a cambios profundos en las actitudes de la sociedad frente a la naturaleza. Ésta pasa de ser una fuente de sustento independiente del control del mercado o del Estado, a ser un recurso económico, lo que implica redefinir cómo es gestionado el medio ambiente, por quién y en beneficio de quién (Hildyard et al. 2012).

\section{Ley de Bosques en Córdoba}

La protección de los bosques nativos por parte del Estado cordobés ha sido deficitaria. De las 12 millones de hectáreas presentes en la provincia a comienzos del siglo XX, sólo quedan en la actualidad 0.64 millones de hectáreas de bosques relativamente bien conservados (Cabido and Zak 2010). Para conocer los efectos de La Ley de Ordenamiento Territorial de Bosques Nativos (en adelante, Ley de Bosques) sobre el acceso a los servicios ecosistémicos de aprovisionamiento de leña 
y madera para los actores sociales vinculados al sector rural, se analizará el caso del oeste de la Provincia de Córdoba. En términos socio-productivos, esta región forma parte de la "zona homogénea árida de Traslasierra de ganadería extensiva" (Ghida Daza and Sánchez 2009). La explotación forestal en la zona reconoce diferentes ciclos, intensidades y sistemas socio-organizativos (Silvetti 2010). Desde la segunda mitad del siglo XX se registra una disminución progresiva de la extracción a gran escala de productos forestales, debido al agotamiento de los bosques y a la caída en el precio del carbón vegetal al sustituirse por combustibles líquidos y gaseosos. La pérdida de rentabilidad de esta actividad permitió la expansión de un ciclo de campesinización basado sobre la explotación forestal de baja escala (principalmente la extracción de madera y leña, y producción de carbón), que cobra gran importancia para la economía doméstica campesina. Esta actividad genera beneficios importantes para este sector porque: a) el ingreso monetario no depende de las incertidumbres climáticas, b) puede realizarse en cualquier época del año permitiendo distribuir mejor el trabajo, y c) se realiza localmente y no implica tiempos adicionales ni costos de desplazamiento, lo que la hace compatible con otras actividades productivas o domésticas (Silvetti 2010).

Los campesinos son el principal tipo social agrario y sus estrategias de vida se centran en el aprovechamiento del bosque nativo a través de la ganadería extensiva (fundamentalmente caprina) (Hocsman 2003; Silvetti 2010). Pero desde hace dos décadas se observa un avance sostenido de la agricultura intensiva (i.e., papa, maíz, soja) y de la ganadería vacuna semiintensiva, llevada adelante por productores capitalizados (Tapella 2012). Hasta hace poco tiempo, el interés productivo por parte de los productores capitalizados y empresarios era escaso y los conflictos que surgían se resolvían a partir de arreglos locales o en base a normas consuetudinarias (Cáceres and Rodríguez Bilella 2014). Las comunidades campesinas que allí habitan utilizaban el agua y las tierras de pastoreo de territorios con relativa libertad, aunque no dispusieran de los títulos de propiedad que les permitieran acreditar su tenencia formal (Hocsman 2003). Las familias que disponían de escasas tierras de pastoreo o de agua negociaban con los vecinos a fin de poder acceder con sus animales a campos colindantes o de productores ausentistas (Cáceres and Rodríguez Bilella 2014). Sin embargo, en la última década del siglo XX $\mathrm{y}$, fundamentalmente, en la primera del siglo XXI, se produjeron cambios significativos como consecuencia de un avance fuerte de los sectores empresariales (Cáceres et al. 2010; Karlin et al. 2013). La inexistencia o la falta de saneamiento de los títulos de propiedad de los campos perjudica a las familias campesinas que ejercían la posesión y uso de esas tierras de pastoreo. Frente a la expansión de los intereses del capital agrario y el avance de la lógica productiva propia del agronegocio, los campesinos enfrentan dificultades para hacer valer sus derechos posesorios (Barbetta 2009; Romano 2011), lo que impacta en sus estrategias productivas.

El presente trabajo busca i) analizar de qué modo la aprobación e implementación de una ley provincial que tiende a la conservación del bosque nativo genera procesos de cercamiento de bienes comunes ("enclosures") y la restricción al acceso al servicio ecosistémico de aprovisionamiento de madera y leña, y ii) discutir cómo esta ley impacta de modo diferencial a distintos actores sociales y profundiza asimetrías económicas en el oeste de la Provincia de Córdoba.

\section{MATERIALES Y MÉTODOS}

Se utilizó una estrategia metodológica de triangulación, que combinó técnicas cuantitativas y cualitativas. En cuanto a las técnicas cualitativas, se realizaron múltiples y recurrentes entrevistas semi-estructuradas en profundidad a informantes calificados y a distintos actores sociales del oeste de la Provincia de Córdoba. En base a guiones elaborados específicamente para cada actor social en función de la información a recabar, se realizaron las entrevistas siguiendo el método de muestreo de "bola de nieve" (Casilimas 1996). Éste consiste en, a partir de un informante clave (como funcionarios o miembros de la comisión de agua), lograr la identificación de otros casos pertinentes para observación. Estos a su vez derivan a nuevos casos sucesivamente hasta alcanzar el criterio de saturación teórica (Trinidad et al. 2006). Entre 2012 y 2015 se entrevistó a 25 productores campesinos, 10 productores capitalizados (5 agrícolas y 5 ganaderos), 4 extensionistas, 4 funcionarios públicos y un referente del Movimiento Campesino de Córdoba. Las entrevistas a los productores se centraron en: i) los cambios en el acceso y aprovechamiento de madera y leña de los bosques nativos por la sanción de la Ley de Bosques, ii) las estrategias de los distintos 
actores para compensar las limitaciones impuestas por la ley, y, por último, iii) sus efectos en la situación económica de cada actor social. A extensionistas, funcionarios y referente del Movimiento Campesino de Córdoba se los consultó sobre: i) el proceso de formulación y sanción de la ley, actores involucrados e intereses representados por cada uno, y ii) la posibilidad de los distintos tipos de productores de acceder a las habilitaciones y compensaciones que prevé la ley, así como sus efectos restrictivos sobre cada grupo. La información obtenida fue registrada en distintas plataformas (principalmente libretas de campo y grabaciones de audio) y sistematizada en matrices de doble entrada (casos y variables) por actor social. La información recabada se ordenó en torno a variables relevantes en función de los ejes por actor social mencionados. Esta información fue contrastada con la recopilación y sistematización de materiales publicados en los medios masivos de comunicación. Esto permitió identificar los posicionamientos y argumentaciones elaboradas por los distintos actores en torno al problema en estudio, así como reconocer la problemática de cercamiento desde la perspectiva de los actores sociales. Asimismo, se revisaron los proyectos presentados en relación a la Ley de Bosques y los fundamentos esgrimidos por los distintos actores sociales durante el proceso legislativo. En función de obtener información cuantitativa del proceso se examinaron los informes mensuales sobre desmontes e infracciones ambientales relevados por la Policía Ambiental de la provincia, y los registros de la ONG Guyra que realiza monitoreos satelitales con información mensualdedesmontes en los departamentos de la Región Chaqueña de Córdoba. Finalmente, se revisaron expedientes y documentos de la Secretaría de Ambiente y los registros de pagos por servicios ecosistémicos realizados por el Estado correspondientes al año 2014. No encontramos, en literatura especializada, ni gris, información que nos permitiera cuantificar las magnitudes de la explotación forestal antes y después de aprobada la ley. Por este motivo se destaca la importancia de la información cualitativa recolectada y la consistencia que se observa al cruzar los datos obtenidos de distintas fuentes.

\section{Resultados}

De las entrevistas a extensionistas, funcionarios y el referente del Movimiento Campesino de Córdoba, junto con la revisión de notas periodísticas y los proyectos de Ley presentados, se pudo reconstruir el proceso de sanción de la Ley de Bosques de Córdoba e identificar los ajustes y los cambios que observó su aplicación durante los primeros años de vigencia. La Ley Nacional de Presupuestos Mínimos de Protección Ambiental de los Bosques Nativos (26331/2007) dispone que las provincias deben realizar un ordenamiento territorial de sus bosques de manera participativa, mediante la sanción de una ley provincial. A tal fin, en Córdoba se conforma la Comisión de Ordenamiento Territorial de los Bosques Nativos (COTBN), integrada por miembros de instituciones gubernamentales y de la sociedad civil (Silvetti et al. 2013). Ante la movilización de distintos sectores que procuraban reflejar sus perspectivas e intereses en la ley provincial, se generan dos grupos de interés que expresan formas diferentes de valorar el bosque nativo y los servicios ecosistémicos que este ofrece. Por un lado, el sector ligado a la lógica productiva del agronegocio centra su interés en la expansión de la producción agropecuaria intensiva, que requiere una remoción total o parcial del bosque. El otro grupo, interesado en la protección del ambiente y las comunidades campesinas, valora la biodiversidad del bosque nativo y destaca la importancia de buscar alternativas productivas que contemplen la sustentabilidad ambiental y social, rechazando el carácter neoextractivista de las perspectivas del primer grupo. Pero debido a disensos que se generaron, los sectores que apoyaban los intereses del primer grupo vinculado al agronegocio abandonaron la COTBN, dejando este espacio dominado por quienes defendían la conservación del bosque nativo y las comunidades campesinas que allí vivían.

Para la elaboración del proyecto de ley, la COTBN realizó un trabajo de campo de dos años que contó con una participación social importante. Además, dentro del anteproyecto que presentaron a la legislatura provincial (COTBN 2009) proponían instancias de participación de las comunidades locales a través de cuerpos de voluntarios (i.e., "guardianes de los bosques") (COTBN 2009: artículo 37). Su propuesta implicaba una importante participación de las sociedades locales en los procesos de toma decisión y en la aplicación y control de la normativa ambiental, ya que consideraba a los bosques nativos como bienes de interés común. Además, tenía en cuenta especialmente a las comunidades campesinas e indígenas como componentes 
centrales de la estructura y funcionamiento de estos ecosistemas. A fin de proteger a estos sectores sociales, establecía que para autorizar proyectos que demandaran la modificación de los bosques nativos donde vivían estas comunidades se requería un consentimiento formal y por escrito de las comunidades, el cual debería ser debatido en una audiencia pública (COTBN 2009: artículo 15). Por otro lado, el sector vinculado a la lógica del agronegocio centró su acción en mostrar al gobierno y a la sociedad cómo las propuestas más proteccionistas en materia ambiental podían afectar a la economía (a la producción agropecuaria en particular) y con ello afectar el crecimiento económico y limitar el progreso de una región considerada marginal desde el punto de vista socioeconómico. En paralelo al trabajo de la COTBN, y sin respetar el protocolo de participación social que ordenaba la ley nacional, este sector elaboró un anteproyecto de ley adecuado a sus intereses y necesidades, que finalmente fue aprobado en la legislatura provincial por 51 votos a favor y 11 en contra (Dirección de Prensa de la Legislatura de Córdoba 2010).

Durante los primeros años de vigencia de la ley, las restricciones a los desmontes y la capacidad de fiscalización fueron escasas e ineficientes. Ante la continuidad de los desmontes ilegales y las repercusiones a nivel mediático, a fines de 2012 se creó la Policía Ambiental de Córdoba (Ley 10115/2012). Manuel Calvo, Ministro de Agua, Ambiente y Energía de la Provincia declaró "...ante un ilícito ambiental en flagrancia, el inspector [de la Policía Ambiental] va a poder actuar con la policía, sin la necesidad de una intervención judicial y de una orden de allanamiento" (La Voz del Interior 2012). Así, la creación de la Policía Ambiental significó un aumento en los controles, multas y decomisos por infracciones a la Ley de Bosques.

\section{El caso del oeste provincial}

Tras la aprobación de la Ley de Bosques de Córdoba segeneran nuevas condiciones legales que regulan el uso y acceso a los servicios ecosistémicos que ofrece el bosque nativo. Las entrevistas a los productores sugieren que estos cambios afectan de forma diferencial a los actores en función de sus condiciones de producción (materiales y culturales). Los campesinos, que tradicionalmente realizaban un aprovechamiento selectivo y variado del monte, son el actor social más perjudicado. Por un lado, se observa que los campesinos que cuentan con títulos de propiedad desus campos son pocos, y este es, precisamente, uno de los requisitos exigidos por la ley para autorizar la explotación forestal. Por otro lado, este actor social en particular enfrenta dificultades para realizar gestiones administrativas ante el Estado debido a sus limitaciones económicas y por su desconocimiento de los canales administrativos y legales propios de la administración pública. En consecuencia, muchos campesinos se ven imposibilitados de: i) solicitar las autorizaciones que les permitirían continuar haciendo el uso del bosque que históricamente realizaban, y ii) gestionar el cobro de compensaciones monetarias por pago de servicios ecosistémicos que contempla la Ley de Bosques. Los pocos campesinos que lograron superar las barreras legales y burocráticas, y que lograron presentar la documentación que solicita la Secretaría de Ambiente, están vinculados con la Unión de Campesinos de Traslasierra (UCATRAS). Ésta integra el Movimiento Campesino de Córdoba (MCC), una organización de asociaciones territoriales de segundo grado con más de 10 años de trabajo organizativo y de articulación con instituciones locales y nacionales en tareas de extensión rural, con importantes luchas reivindicativas por la protección del medio ambiente y los territorios campesinos. La experiencia y pericia de esta organización en la gestión de trámites y proyectos en el Estado les ha permitido a algunos campesinos vinculados al MCC acceder a las habilitaciones de uso del bosque que autoriza el gobierno provincial, y/o a las compensaciones que ofrece la ley. A través de declaraciones juradas y actas firmadas por un juez de paz, han logrado que campesinos que ocupaban tierras en forma precaria pasen a integrar el Registro Personal de Poseedores creado por la Ley 9150/2004. Si bien la inscripción en este registro no resuelve los conflictos que enfrentan por la propiedad de sus tierras, les permite gestionar permisos deaprovechamiento forestaly compensaciones por conservación de bosque nativo.

En contraste, los productores capitalizados de la zona son empresarios abocados a la producción bovina semi-intensiva o a la agricultura intensiva. En ambos casos, sus actividades productivas requieren inversiones altas en capital inmueble (e.g., instalaciones ganaderas o perforaciones para la extracción de agua para riego) y, por lo tanto, operan en campos cuya propiedad está regularizada. Debido al patrón productivo de esta región, en una misma explotación pueden coexistir actividades agrícolas y ganaderas con 
algunas porciones de bosque sujetas a un uso más extensivo. En estas áreas menos intervenidas pueden desarrollar actividades forestales tales como la extracción de leña o producción de carbón. Si se encuentran en buen estado de conservación pueden solicitar las compensaciones por pago de servicios ecosistémicos que dispone la ley provincial. A diferencia de los campesinos, estos productores disponen de mayor poder económico y político, lo que les permite acceder de una manera más fluida a los niveles de decisión del Estado provincial. Tampoco tienen mayores inconvenientes para reunir los requisitos legales o realizar los trámites administrativos que exige la ley provincial.

Autorizaciones para uso forestal. Para el transporte o tenencia de productos o subproductos forestales, la reglamentación ambiental vigente exige la tramitación de Guías Forestales de Bosque Nativo (Ley 9814/ 2010: artículo 46-h). Para obtener estas guías, el titular del campo debe ser autorizado por la Secretaría de Ambiente, mediante resolución o nota, a realizar trabajos de desmonte, acopios, aprovechamiento de leña seca o limpieza de alambrados. Como se señala en la sección anterior, esto constituye un obstáculo para muchos campesinos quienes ven limitadas sus posibilidades de explotación del bosque nativo. Esta es la perspectiva de algunos de los entrevistados:

"... Se cortó mucho los bosques antes para hacer carbón, que eso sí hacían mucho carbón, y habia mucha vida entonces para la gente pobre, porque hachaban la madera, la leña seca, hacían el carbón, así que el que tenía campo siempre lo explotaba (...). No habian tantas leyes como ahora [en referencia a la Ley de Bosques]. Le digo una cosa hoy en día no dejan cortar el monte, no dejan cortar..." (RB y DB, campesinos de El Cadillo, 10 de marzo de 2015).

“... La gente que vive acá vive de los animales, no tienen otro medio. Acá no lo dejaron hachar más ni hacer un carbón ni cortar un palo de leña, nada... Antes [de la Ley de Bosques] no, era distinto. Antes uno trabajaba el monte y todo. Con el carbón compraba la mercadería y tenía para el invierno, y ahora ya no..." (EQ, campesino de El Quemado, 25 de junio de 2014).

La comercialización constituye el principal obstáculo que enfrentan estos productores, ya que para sacar los productos forestales del campo, indefectiblemente necesitan las guías que exige la Ley. Al no disponer de títulos de propiedad de sus campos, o al no poder tramitar su acceso en el Registro Personal de Poseedores, no disponen del requisito básico e indispensable para gestionar la obtención de las guías forestales. Además, los gastos de gestión y desplazamiento y el acceso a la información necesarios para realizar los trámites, generalmente están fuera de su alcance. Sin estas guías, no pueden vender o intercambiar ningún tipo de producto forestal, como sí ocurría antes de aprobada la Ley de Bosques. Así lo reflejan algunos de los entrevistados:

"...Y antes podian vender el carbón tranquilamente, no había que sacar guía, nada. Venían los que compraban de San Juan por decirte siempre ha sido acá donde más compraban la madera, compraban el carbón y no habia problema para venderla, cada cual hacía un horno de carbón o lo que podía o lo que tenía, vivía tranquilo. Tenía para trabajar en el invierno. Pero ahora no se puede, hay que denunciar el campo, ver que el monte esté en regla, que cuánto hay que dejar, que cuánto hay que cortar y hacer un montón de trámites para que le den guí..." (RB y DB, El Cadillo, 10 de marzo de 2015).

"...Si usted corta un palo de leña como para vender un chasis de leña, vamos a decir, no hay quién lo compre porque no tenemos guía... Más antes [de la Ley de Bosques] no había ninguna cosa de esas..." (MM, Santa Rosa, 24 febrero de 2015).

La nueva legislación opera como un cercamiento para los actores locales más vulnerables, que limita su acceso a servicios ecosistémicos claves para su reproducción social. En contraste, los productores capitalizados acceden a distintos mecanismos para continuar con las actividades de extracción de madera y leña y/o se benefician por la entrega de compensaciones de parte del gobierno provincial. Esto no quiere decir que estos productores puedan hacer un uso discrecional del monte ya que, en términos comparativos con lo que ocurría antes de la aprobación de la Ley de Bosques, ahora enfrentan más restricciones. No obstante, a partir de la triangulación de la información publicada por la Policía Ambiental, los registros mensuales de deforestación de la ONG Guyra y las declaraciones de funcionarios y de organizaciones sociales se corrobora que después de la aprobación de la Ley de Bosques han continuado los desmontes en la Provincia de Córdoba. Los informes extendidos de Guyra indican que entre 2012 
y 2014 se desmontaron en la Provincia de Córdoba 14823 ha de monte chaqueño, una tasa de casi 5000 ha/año.

Los procesos por los que se producen los desmontes o aprovechamientos forestales después de la aprobación de la Ley de Bosques son dos. El primero es la vía administrativa, que consiste en realizar las gestiones requeridas para lograr las autorizaciones formales. Esta metodología ha generado algunos conflictos legales y disputas políticas ya que las autorizaciones otorgadas por la Secretaría de Ambiente no siempre estuvieron encuadradas en el marco legal que regula la Ley de Bosques. En el 2015, algunas organizaciones sociales (el Movimiento Campesino de Córdoba y el Foro Ambiental Córdoba) denunciaron públicamente que la Secretaría de Ambiente había autorizado desmontes en zonas no permitidas por la Ley de Bosques. La denuncia

Tabla 1. Compensaciones monetarias recibidas por productores agropecuarios de la Provincia de Córdoba, como retribución por los servicios ecosistémicos que ofrece el bosque nativo. Los pagos corresponden al año 2014.

Table 1. Monetary compensation received by farmers in the province of Córdoba, as payment for ecosystem services provided by native forests. Payments are for year 2014.

\begin{tabular}{lcccc}
\hline \multicolumn{1}{c}{ Tipo de } & \multicolumn{2}{c}{ Número de Porcentaje } & Monto & Porcentaje \\
productor & beneficiarios & {$[\%]$} & compensado[\$] & {$[\%]$} \\
\hline $\begin{array}{l}\text { Campesinos } \\
\text { Productores }\end{array}$ & 35 & 7.26 & 1339838.76 & 9.96 \\
$\begin{array}{l}\text { capitalizados } \\
\text { Total }\end{array}$ & 447 & 92.74 & 12105977.14 & 90.04 \\
\hline
\end{tabular}

comprendía unas 6500 ha correspondientes a cinco explotaciones agropecuarias ubicadas en el noroeste y oeste de la Provincia de Córdoba, pertenecientes todas ellas a productores capitalizados (La Mañana de Córdoba 2015; El Argentino 2015; Cba24n 2015). En forma paralela, una investigación periodística de PRENSARED (la agencia de noticias del Círculo Sindical de la Prensa y la Comunicación de Córdoba - CISPREN) tuvo acceso a información confidencial de la Secretaría de Ambiente y señaló que fueron 20000 las hectáreas autorizadas de manera irregular para desmonte, ya que no se siguieron los procedimientos técnicos que la Ley de Bosques ordena explícitamente. En medio de denuncias por corrupción y desmentidas por parte del gobierno, en el último trimestre de 2015 se produjeron las renuncias del Director de Bosques y del Secretario de Ambiente de la Provincia de Córdoba (PRENSARED 2015; Sala de Prensa Ambiental 2015). La segunda vía es mediante la infracción directa por parte de los productores, sin mediar autorización a la Secretaría de Ambiente. Esta opción implica la realización de desmontes clandestinos o aprovechamientos ilegales del bosque, donde el propietario asume los riesgos de multa por la infracción cometida y/o el decomiso de los productos forestales durante el transporte debido a la ausencia de guías forestales. El 63\% de las hectáreas de bosque nativo intervenidas entre septiembre de 2014 y octubre de 2015, identificadas por la Policía Ambiental a través de monitoreo satelital, no estaban autorizadas por la Secretaría de Ambiente y por lo tanto

Tabla 2. Implicancias de la Ley de Protección de Bosques Nativos (Ley 9814/2010) sobre el acceso, las estrategias productivas y la situación económica de los distintos tipos de productores del oeste de la Provincia de Córdoba, Argentina.

Table 2. Implications of the Law for the Protection of Native Forests (Law 9814/2010) on the access, the productive strategies and the economy of the different types of farmers in Western Córdoba, Argentina.

\begin{tabular}{|c|c|}
\hline Eje & Implicancias \\
\hline $\begin{array}{l}\text { Cambios en } \\
\text { el acceso y } \\
\text { aprovechamiento } \\
\text { de los servicios } \\
\text { ecosistémicos } \\
\text { madera y leña }\end{array}$ & $\begin{array}{l}\text { Campesinos: en casi todos los casos están imposibilitados de continuar con la venta e intercambio de estos } \\
\text { productos. } \\
\text { Productores ganaderos: la extracción forestal es una actividad secundaria en su planteo de producción ganadera. } \\
\text { Se encuentran ante tres opciones: abandonar la actividad extractiva, disminuirla (atendiendo a los controles y } \\
\text { autorizaciones) o continuarla, a riesgo de ser multado. } \\
\text { Productores agrícolas: el interés por la extracción forestal está supeditado a la posibilidad de desmontar para } \\
\text { habilitar nuevas tierras para la agricultura. La venta de productos forestales no representa un ingreso económico } \\
\text { significativo. }\end{array}$ \\
\hline $\begin{array}{l}\text { Estrategias de los } \\
\text { distintos actores } \\
\text { para compensar } \\
\text { las limitaciones } \\
\text { que genera la ley }\end{array}$ & $\begin{array}{l}\text { Campesinos: sólo algunos de los vinculados a organizaciones campesinas pueden realizar los trámites } \\
\text { administrativos requeridos para poder explotar el bosque nativo u obtener compensaciones por la conservación } \\
\text { del bosque nativo. } \\
\text { Productores ganaderos: tiene las herramientas legales y culturales para gestionar permisos de explotación y } \\
\text { obtener compensaciones. } \\
\text { Productores agrícolas: cuando poseen áreas con bosque en buen estado de conservación, tramita el pago de } \\
\text { compensaciones. }\end{array}$ \\
\hline $\begin{array}{l}\text { Efectos en } \\
\text { la situación } \\
\text { económica } \\
\text { de cada tipo } \\
\text { productivo }\end{array}$ & $\begin{array}{l}\text { Campesinos: pierden una fuente de ingreso importante. Disminuye su flexibilidad productiva ya que realizaban la } \\
\text { extracción forestal cuando disminuía la demanda de trabajo. } \\
\text { Productores ganaderos: el impacto económico está parcial o totalmente compensado, porque puede continuar con } \\
\text { la extracción de madera y leña, y/o recibir compensaciones monetarias. } \\
\text { Productores agrícolas: Puede verse limitada su posibilidad de expandir el área agrícola (por las restricciones al } \\
\text { desmonte), aunque esta limitación no está ligada al acceso al aprovisionamiento de leña y madera. }\end{array}$ \\
\hline
\end{tabular}


vulneraban las disposiciones establecidas en la Ley de Bosques. Durante el 2014, un total de 96 infractores fueron multados por desmontar, transportar o acopiar productos forestales sin las guías o autorizaciones correspondientes. Asimismo, en el mismo período de septiembre de 2014 a octubre de 2015 la Policía Ambiental constató el desmonte ilegal de 9445 ha. Lamentablemente, no hay datos posteriores a octubre de 2015 publicados por la Policía Ambiental a la fecha (revisado por última vez en julio de 2016).

Compensaciones monetarias. Otro mecanismo que favorece la acumulación desigual en favor de los productores que acreditan propiedad legal de la tierra es la entrega de compensaciones monetarias con el objeto de "resarcir a los titulares que conserven el bosque nativo por los servicios ambientales que éstos brindan" (Ley 9814/2010: artículo 20-h). A tal fin, las provincias reciben del gobierno federal un Fondo Nacional para el Enriquecimiento y la Conservación de los Bosques Nativos, del cual un 70\% está destinado a la compensación para los dueños de campos que conserven el bosque. En Córdoba, el primer pago se efectivizó en el 2015 y compensaba los servicios ecosistémicos correspondientes al 2014 (Tabla 1). Esas compensaciones totalizaron $\$ 13.45$ millones (1.5 millones de dólares estadounidenses según la cotización del día en que se aprobó la Resolución SAyDS No 1412). Este subsidio se distribuyó entre aquellos productores cuyas solicitudes fueron aprobadas por la Secretaría de Ambiente y posteriormente avaladas por el gobierno nacional.

Debido a las razones que se presentan en las secciones anteriores, la gran mayoría de los beneficiarios (447 productores, $92.74 \%$ ) fueron productores capitalizados. No obstante, con el apoyo de su organización, 35 campesinos asociados al Movimiento Campesino de Córdoba pudieron realizar los trámites requeridos y beneficiarse con algunas de las compensaciones. Sin embargo, si se tiene en cuenta que alrededor de 600 familias campesinas están nucleadas en torno al MCC, se observa que aun entre los campesinos federados el número de beneficiarios ha sido muy bajo ( 6\%). Lo propio ocurrió con los recursos económicos ya que recibieron el 10\% de las compensaciones monetarias. A modo de síntesis, la Tabla 2 señala como la Ley de Bosques impacta sobre los distintos tipos de productores.

\section{Discusión}

La Ley de Bosques, fundamentada en la conservación ambiental, genera cambios en el acceso a servicios ecosistémicos, que impactan de forma diferenciada sobre los actores sociales y afecta especialmente a los sectores sociales más vulnerables. El proceso de tratamiento, aprobación y reglamentación de la Ley de Bosques en la Provincia de Córdoba resulta un caso paradigmático en esta discusión. Esta ley permite vincular los conceptos de servicios ecosistémicos, cercamientos, bienes comunes y acumulación por desposesión, en un marco de disputa y conflictividad social donde emergen y se sostienen distintos posicionamientos político ideológicos (Cáceres et al. 2016).

El concepto de "green grabbing" aporta herramientas para analizar este caso. El término aparece por primera vez en el artículo publicado por John Vidal (2008) en el periódico inglés The Guardian, para hacer referencia al fenómeno de compra de tierras en países en desarrollocon fines conservacionistas. Algunos autores vinculan esta lógica de conservación con motivaciones colonialistas que pueden atentar contra la autodeterminación de países y/o comunidades locales sobre sus propios territorios (Baletti 2012; Fairhead et al. 2012), como así también promover procesos de mercantilización de la naturaleza y vincular la conservación de los ecosistemas con la lógica de los mercados (Holmes 2014). Estas apropiaciones implican acumulación por el traspaso de propiedad, derechos o control sobre territorios, que pueden haber estado sujetos a regímenes de propiedad privada o pública (o incluso no estar afectados por ningún régimen de propiedad), a actores concentradores de capital. A su vez puede desencadenar procesos de desposesión sobre sectores socialmente vulnerables, limitando su acceso a recursos o servicios ecosistémicos claves para su reproducción social (Fairhead et al. 2012).

Desde una perspectiva más general, el "green grabbing" se produce en cualquier caso en que, con fundamentos de conservación, se excluyen o limitan a las comunidades de la propiedad, el acceso, o el aprovechamiento de territorios o recursos, independientemente de que estos sean o no apropiados por particulares. Así, el "green grabbing" como mecanismo de exclusión se complementa con otros procesos tales como los producidos por los cercamientos o "enclosures" (Corson and MacDonald 2012). A diferencia del fenómeno denominado "land 
grabbing" (Borras et al. 2012), el "green grabbing" no siempre implica una restricción total al acceso a la tierra y a los recursos por parte de las comunidades locales. Por el contrario, en muchos casos se trata de una reestructuración de las reglas sobre el acceso, el uso y el manejo que origina procesos de restricción al acceso a determinados recursos para uno o más actores sociales (Fairhead et al. 2012).

Los procesos de cercamiento de los bienes comunes (Fernández 1993a; Ostrom 2000; Houtart 2015), cuando conciernen a ecosistemas, condicionan el aprovisionamiento y acceso a los servicios ecosistémicos. La defensa de los bienes comunes y de su disponibilidad para los sectores sociales más vulnerables se presenta como una alternativa al enfoque hegemónico actual, de carácter fundamentalmente economicista. Desde esta perspectiva son relevantes las dimensiones social y ecológica que, en enfoques economicistas, son desestimadas o subvaloradas, y consideradas como externalidades al momento de tomar o evaluar decisiones. Efectivamente, en el contexto del marco regulatorio actual, no es el capital quien soporta los efectos negativos en materia socioambiental, sino las comunidades locales a través de la pérdida de acceso a los servicios ecosistémicos de los que dependen (Houtart 2015).

En el caso del oeste de la Provincia de Córdoba, se observa la incidencia de dos procesos simultáneos. Desde el punto de vista económico, el nuevo patrón productivo que se despliega en la región como consecuencia de la lógica vinculada al agronegocio se refleja en la ocurrencia de cercamientos que limitan el acceso campesino a territorios a los que históricamente habían tenido acceso. Desde el punto de vista legal, la promulgación de la Ley de Bosques genera nuevas normas que regulan la explotación de los bosques nativos por parte de los productores agropecuarios. Las diferencias económicas, sociales y políticas que existen entre campesinos y productores capitalizados que operan en el oeste de Córdoba se traducen en diferentes abordajes productivos y en muy distintas estrategias de uso del bosque nativo. Un aspecto que resulta necesario destacar, ya que es relevante a la discusión que se plantea en el presente trabajo, tiene que ver con los distintos tipos de propiedad presentados en la sección introductoria. Con frecuencia, los campesinos de esta región combinan dos de las categorías mencionadas: propiedad privada y comunal. Aun cuando a menudo no pueden justificar la tenencia legal de las tierras que ocupan (Hocsman 2003; Barbetta 2009; Romano 2011), consideran como propios los territorios que su grupo familiar ha venido utilizando durante generaciones. Sin embargo, también han utilizado históricamente tierras de terceros (e.g., otros campesinos o productores ausentistas), sujetas a un uso que podría ser descripto como comunal. Del mismo modo, y como consecuencia de arreglos locales y negociaciones con sus vecinos, también toleran el ingreso de animales de terceros a los campos que ellos consideran "propios". El concepto de propiedad comunal, no es entonces ajeno al tipo de uso con el que están familiarizados los campesinos. Por el contrario, forma parte de una estrategia que proporciona mayor resiliencia a sus sistemas productivos, a la vez que favorece un acceso menos restrictivo a los servicios ecosistémicos que ofrece el bosque. Pero como señalan Cáceres and Rodríguez Bilella (2014), esto no implica que este acceso sea libre, sino que está regulado por normas consuetudinarias que estas comunidades han ido negociando y consensuando a lo largo de la historia.

En contraste, los productores capitalizados con un perfil empresarial sustentan su estrategia económico-productiva en una estructura legal de tenencia de la tierra basada en la propiedad privada, y casi siempre desarrollan sus actividades productivas en campos en los que pueden acreditar formalmente este tipo de propiedad. Debido a las particularidades de su lógica productiva, el tipo de rubros que producen y la magnitud de las inversiones que realizan, la propiedad privada es la categoría jurídica que mejor se adecua a sus intereses. Evidentemente, este tipo de enfoque productivo, no es compatible con el tipo de uso flexible y menos restrictivo propio de la lógica campesina.

Resulta interesante observar cómo una normativa legal que pone el foco en la conservación de uno de los ecosistemas más importantes de Argentina no se adecua a la concepción que los campesinos tienen sobre el uso del territorio y el acceso a los servicios ecosistémicos que ofrece el bosque nativo. Ésta prioriza la idea de propiedad privada por sobre las normas consuetudinarias, los arreglos locales, el acceso flexible y el uso del bosque nativo, sobre la base de una lógica que contempla la concepción de los bienes comunes. Al igual que en otros casos, nuevas 
reglamentaciones ambientales convierten en actividades ilegales las prácticas tradicionales de las comunidades locales (Hansen et al. 2015). Como la extracción de madera y leña constituía uno de los pilares en los que se basaban las estrategias de reproducción social campesinas, con la nueva normativa se ve resentido uno de los ingresos principales sobre los que se asienta su economía doméstica. En contraste, los productores capitalizados han encontrado mecanismos legales e ilegales que les permiten continuar con la extracción forestal. Por lo tanto, la nueva legislación ambiental genera también nuevas condiciones sociales que se traducen en asimetrías y nuevas inequidades socioeconómicas entre actores productivos que operan en el mismo territorio. Al ser los actores con menos poder los más perjudicados, se profundizan aún más las diferencias entre estos sectores productivos, lo que está en consonancia con los procesos globales de acumulación por desposesión que se observan en otras regiones de Argentina y Latinoamérica.

El vínculo con otros procesos similares en los que el cercamiento de bienes comunes se produce bajo justificaciones de conservación ambiental (i.e., "green grabbing"), indica que el caso de Córdoba, está enmarcado en una tendencia global. En un mundo donde domina una lógica económica de mercado, los ecosistemas están sujetos de una manera creciente a una lógica extractivista que prioriza la rentabilidad de corto plazo (Svampa 2006). El reemplazo de los bosques nativos por agricultura industrial $u$ otras actividades que implican un cambio drástico en el uso del suelo, afecta los servicios ecosistémicos que estos brindan a la sociedad, a la vez que genera pasivos ambientales. Dada su importancia social, el Estado tiene la responsabilidad de proteger estos ecosistemas a fin de garantizar el bienestar social. Pero toda nueva reglamentación ambiental debería considerar cuestiones de equidad, como también sus posibles impactos ecológico, económicos y sociales (Pascual et al. 2014). En particular, las necesidades e intereses de los sectores sociales más vulnerables quienes, en muchos casos, tienen una dependencia elevada de estos servicios ecosistémicos. De lo contrario, las nuevas normativas ambientales pueden acentuar las asimetrías e inequidades sociales y favorecer los procesos de concentración económica y acumulación por desposesión.

Finalmente, este trabajo también abre a la discusión de nuevos interrogantes: ¿se mantendrán las asimetrías observadas cuando se realicen las próximas compensaciones? La rediscusión de la Ley de Bosques (actualmente en curso), ¿introducirá nuevos criterios y valoraciones que modifiquen el modo en que los actores se apropian de sus beneficios? ¿Influirán los cambios en la política nacional en el financiamiento futuro de la ley? Si no se ajusta el presupuesto destinado a compensaciones, ¿estarán los distintos tipos de productores igualmente interesados en acogerse a los beneficios que ofrece la ley? Se requieren nuevas investigaciones a fin de conocer la dinámica futura del proceso.

Agradecimientos. Agradecemos al Movimiento Campesino de Córdoba, al Foro Ambiental Córdoba, a F. Kopta y a D. Tamburini. También hacemos llegar nuestro reconocimiento al CONICET, la Universidad Nacional de Córdoba y la SECyT-UNC.

\section{REFERENCIAS}

Aladró, M. I. 1993. Del aprovechamiento común a la gestión privada: el coto de caza de Buiza de Gordon (León). Pp. 197-203 en: J. P. Fernández (coord.). Procesos de apropiación y gestión de recursos comunales. Asociación Canaria de Antropología, Tenerife. España.

Baletti, B. 2012. Ordenamento Territorial: Neo-developmentalism and the struggle for territory in the lower Brazilian Amazon. The Journal of Peasant Studies 39:573-598.

Barbetta, P. 2009. En los bordes de lo jurídico. Conflictos por la tenencia legal de la tierra en Santiago del Estero. Tesis doctoral. Universidad Nacional de Córdoba, Argentina. Pp. 219.

Benkler, Y. 2008. La economía política del procomún. [1] Pp. 127-137 en: S. Helfrich (comp.). Genes, bytes y emisiones: bienes comunes y ciudadanía. Ediciones Böll, México.

Blomley, N. 2007. Making private property: enclosure, common right and the work of hedges. Rural History 18:1-21.

Borras, S. M., C. Kay, S. Gómez, and J. Wilkinson. 2012. Land Grabbing and Global Capitalist Accumulation: Key Features in Latin America. Canadian Journal of Development Studies 33:402-416.

Cabido, M. C., and M. Zack. 2010. Deforestación, agricultura y biodiversidad. Apuntes sobre el panorama global y la realidad de Córdoba. Hoy la Universidad. Disponible en www.hoylauniversidad.unc.edu.ar/2010/junio/

Cáceres, D. M., G. Soto, G. Ferrer, F. Silvetti, and C. Bisio. 2010. La Expansión de la Agricultura Industrial en Argentina Central. Su Impacto en las Estrategias Campesinas. Cuadernos de Desarrollo Rural 7:91-119.

Cáceres, D. M., and P. Rodríguez-Bilella. 2014. Acceso y apropiación del agua en comunidades rurales pobres de Argentina central: Transformaciones y conflictos. Economía, sociedad y territorio 14:359-395. 
Cáceres, D. M. 2015. Accumulation by Dispossession and Socio Environmental Conflicts Caused by the Expansion of Agribusiness in Argentina. Journal of Agrarian Change 15:116-147.

Cáceres, D. M., F. Silvetti, and S. Díaz. 2016. The rocky path from policy-relevant science to policy implementation - a case study from the South American Chaco. Current Opinion in Environmental Sustainability 19:57-66.

Casilimas, C. A. 1996. Investigación cualitativa. Icfes, Bogotá, Colombia.

Cba24n. 2015. Denuncian nuevos desmontes en Traslasierra y Villa Quilino. 30/09/2015. Disponible en www.cba24n.com.ar/content/denuncian-nuevos-desmontes-en-traslasierra-y-villa-quilino

Corson, C., and K. I. MacDonald. 2012. Enclosing the global commons: the convention on biological diversity and green grabbing. Journal of Peasant Studies 39:263-283.

COTBN. 2009. Proyecto de Ley de Ordenamiento Territorial de Bosques Nativos de la Provincia de Córdoba. Córdoba Argentina. Disponible en archivo.lavoz.com.ar/anexos/Informe/09/7090.pdf

Dirección de Prensa de la Legislatura de Córdoba. 2010. Córdoba cuenta ya con una ley que regula los bosques nativos de la provincia. 04/08/2010. Disponible en www.prensalegiscba.gob.ar/boletin/14-informacion-general/645-cordobacuenta-ya-con-una-ley-que-regula-los-bosques-nativos-de-la-provincia/

El Argentino. 2015. Denunciaron desmontes en zonas protegidas del noroeste provincial. 01/10/2015. Disponible en elargentinocordoba.infonews.com/nota/252941/denunciaron-desmontes-en-zonas-protegidas

Fairhead, J., M. Leach, and I. Scoones. 2012. Green Grabbing: a new appropriation of nature? Journal of Peasant Studies 39:237-261.

Feeny, D., F. Berkes, B. J. McCay, and J. M. Acheson. 1990. The tragedy of the commons: twenty-two years later. Human Ecology 18:1-19.

Fernández, J. P. 1993a. Apuntes para el debate en torno a la tragedia de los comunes. Pp. 23-46 en: J. P. Fernández (coord..). Procesos de apropiación y gestión de recursos comunales. Asociación Canaria de Antropología, Tenerife, España.

Fernández, J. P. 1993b. Introducción. Pp. 7-12 en: J. P. Fernández (coord.). Procesos de apropiación y gestión de recursos comunales. Asociación Canaria de Antropología, Tenerife, España.

Ghida-Daza, C., and C. Sánchez. 2009. Zonas Agroeconómicas Homogéneas Córdoba. Buenos Aires: Instituto Nacional de Tecnología Agropecuaria, Argentina.

Hansen, M., M. Islar, and T. Krause. 2015. The Politics of Natural Resource Enclosure in South Africa and Ecuador. Conservation And Society 13:287.

Harvey, D. 2007. Breve historia del neoliberalismo. AKAL, Madrid, España.

Harvey, D. 2004. El Nuevo Imperialismo. AKAL, Madrid, España.

Helfrich, S., and J. Hass. 2008. Genes, bytes y emisiones: acerca del significado estratégico del debate de los bienes comunes. Pp. 311-328 en: S. Helfrich (comp.). Genes, bytes y emisiones: bienes comunes y ciudadanía. Ediciones Böll, México.

Hildyard, N., L. Lohmann, and S. Sexton. 2012. Energy security for whom? For what? Dorset: The corner house.

Hocsman, L. D. 2003. Reproducción Social Campesina: tierra, trabajo y parentesco en el Chaco Árido Serrano. Centro de Estudios Avanzados, Universidad Nacional de Córdoba, Argentina.

Holmes, G. 2014. What is a land grab? Exploring green grabs, conservation, and private protected areas in southern Chile. Journal of Peasant Studies 41:547-567.

Houtart, F. 2015. De los bienes comunes al bien común de la humanidad. Alter-nativa. Revista de Estudios Rurales 1:52-90.

Illich, I. 1983. Silence is a Commons. CoEvolution Quarterly 40:5-9.

Karlin, M. S., U. O. Karlin, R. O. Coirini, G. J. Reati, and R. M. Zapata. 2013. El Chaco Árido. Encuentro Grupo Editor, Córdoba, Argentina.

La Voz del Interior. 2012. En año récord de desmonte, crean la policía ambiental. 18/10/2012. Disponible en www.lavoz.com.ar/ciudadanos/ano-record-desmonte-crean-policia-ambiental

La Mañana de Córdoba. 2015. Denuncian la aprobación de desmontes en el noroeste cordobés. 01/10/2015. Disponible en www.lmcordoba.com.ar/nota/217899_denuncian-la-aprobacion-de-desmontes-en-el-noroeste

Marx, K. 1976. El Capital. Penguin Books. New York, USA.

Ostrom, E. 2000. El gobierno de los bienes comunes: la evolución de instituciones de acción colectiva. Universidad Nacional Autónoma de México.

Pascual, U., J. Phelps, E.Garmendia, K. Brown, E.Corbera, A. Martin, E. Gomez-Baggethun and R.Muradian. 2014. Social equitymatters in payments for ecosystem services. BioScience 64:1027-1036.

PRENSARED. 2015. Desmontes ilegales/Grave denuncia contra el ex secretario de Ambiente de la Provincia. 04/12/ 2015. Disponible en www.prensared.org.ar/34657/ex-secretario-de-ambiente-de-la-provincia-promovia-desmontesilegales

Romano, M. 2011. Nosotros siempre fuimos campo abierto. Conflictos territoriales, derechos a la tierra y poder judicial en el norte de Córdoba. Tesis doctoral. Universidad Nacional de Córdoba, Argentina. Pp. 291.

Sala de Prensa Ambiental. 2015. El ex -secretario de ambiente promovía desmontes ilegales.

Silvetti, F. 2010. Estrategias Campesinas, Construcción Social del Hábitat y Representaciones sobre la Provisión de Servicios Ecosistémicos en el Chaco Arido. Un Análisis Sociohistórico en el Departamento Pocho (Córdoba, Argentina). 
Tesis doctoral. Universidad Nacional de Córdoba, Argentina.

Silvetti, F., G. Soto, D. M. Cáceres, and D. A. Cabrol. 2013. ¿Por qué la Legislación no Protege a los Bosques Nativos de Argentina? Conflictos Socioambientales y Políticas Públicas en la Provincia de Córdoba. Mundo Agrario 13.

Svampa, M. 2006. Movimientos sociales y nuevo escenario regional: Las inflexiones del paradigma neoliberal en América Latina. Cuadernos del CISH (19-20):141-155.

Tapella, E. 2012. El Conflicto Social en Torno a la Apropiación de Servicios Ecosistémicos en el Oeste de la Provincia de Córdoba. La Posición de los Actores Sociales más Vulnerables. Tesis doctoral, Universidad Nacional de Córdoba, Argentina.

Trinidad, A., V. Carrero, and R. Soriano. 2006. Teoría fundamentada "grounded theory": La construcción de la teoría a través del análisis interpretacional. Centro de Investigaciones Sociológicas. Madrid, España.

Vercelli, A., and H. Thomas. 2008. Repensando los bienes comunes análisis socio-técnico sobre la construcción y regulación de los bienes comunes. Pp. 49-62 en: S. Helfrich (comp.). Genes, bytes y emisiones: bienes comunes y ciudadanía. Ediciones Böll, México.

Vidal, J. 2008. The great green land grab. The Guardian 13.

Leyes citadas

Ley 9150. 2004. SANEAMIENTO DE TÍTULOS - REGISTRO DE POSEEDORES DE INMUEBLES. Legislatura de la Provincia de Córdoba.

Ley 26331. 2007. PRESUPUESTOS MINIMOS DE PROTECCION AMBIENTAL DE LOS BOSQUES NATIVOS. Senado y Cámara de Diputados de la Nación Argentina.

Ley 9814. 2010. ORDENAMIENTO TERRITORIAL DE BOSQUES NATIVOS DE LA PROVINCIA DE CÓRDOBA. Legislatura de la Provincia de Córdoba.

Ley 10115. 2012. CREACIÓN DE LA DIRECCIÓN DE POLICÍA AMBIENTAL DEPENDIENTE DEL MINISTERIO DE AGUA, AMBIENTE Y ENERGÍA DE LA PROVINCIA. Legislatura de la Provincia de Córdoba. 